\title{
O Sistema do Tratado Antártico: a consolidação de um regime internacional e o debate sobre seu déficit democrático
}

\author{
Antarctic Treaty System: \\ the consolidation of an international regime \\ and its democratic deficit debate
}

Daniela Portella Sampaio*

\section{Resumo}

A consolidação do Sistema do Tratado Antártico (STA) fundamenta-se na legitimidade de seus atributos, mesmo quando estes não são considerados democráticos. Assim, com base nos debates sobre a viabilidade democrática em organizações internacionais e no papel dos atores externos epistêmicos em legitimar instituições de governança global, analisa-se a trajetória do STA e a problemática de seu déficit democrático, destacando as críticas à sua hierarquia interna e a seu exclusivismo externo. Conclui-se que o STA é bem-sucedido devido à necessidade de expertise para seu processo decisório e à legitimidade aferida por organismos científicos que orientam o caráter pacífico das atividades.

Palavras-chave: Antártica; Sistema do Tratado Antártico; Governança global; Déficit democrático; Legitimidade

\section{Abstract}

The Antarctic Treaty System (STA) consolidation is established upon the legitimacy of its attributes, even when they are not considered democratic. Thus, based on the debates about the democratic viability in international organizations, and the role of external epistemic actors in legitimizing global governance institutions, this work analyzes the trajectory of the STA and its democratic deficit problematic, highlighting criticisms to its internal hierarchy and external exclusivism. It is concluded that the demand for expertise in decision making and the legitimacy supplied by scientific organizations are the main reasons for STA legitimated consolidation.

Key words: Antarctica; Antarctic Treaty System; Global governance; Democratic deficit; Legitimacy

\footnotetext{
* Doutoranda em Relações Internacionais pela Universidade de São Paulo e PhD Visiting Student na Royal Holloway University of London, Department of Geography. Bolsista de Doutorado Sanduíche no Exterior - CNPq (agradecimentos pelo auxílio concedido para a realização desta pesquisa). E-mail: danirics@usp. br
} 


\section{Introdução}

O quão fundamental é a democracia para se aferir legitimidade às instituições internacionais de governança global levanta importantes análises e interpretações sobre os diversos regimes internacionais em voga. Este é o caso do Sistema do Tratado Antártico. Criado a partir da suspensão de reivindicações por soberanias territoriais na região nos anos 1960, este regime internacional se consolidou e evoluiu a partir da manutenção de um arranjo institucional que não resolvia a questão da soberania, mas que garantia uma hierarquia interna entre seus membros e uma distinção com relação aos atores externos a ele. 0 poder exclusivo de veto e voto pelos membros consultivos é um dos fatores mais significativos com relação aos questionamentos da legitimidade do Tratado Antártico e foi objeto de fortes críticas nos anos de 1970 e 1980 por parte de Estados não signatários e da própria Assembleia Ceral das Nações Unidas. As razões que justificavam esse isolamento institucional antártico eram relacionados à necessidade de preservar para melhor conhecer a região, desdobrando-se em uma forte orientação institucional em prol da pesquisa científica e da preservação ambiental. Além disso, a potencialidade subjacente de tensões e conflitos na região levou à preocupação de se manter a paz e isso implicava o temor de uma participação desenfreada de atores externos e dos diversos interesses paralelos que inevitavelmente a acompanhariam.

Todavia, a identificação de um déficit democrático no Sistema do Tratado Antártico não comprometeu seu processo de consolidação. Pelo contrário, países antes críticos, como Índia e Malásia, tornaram-se signatários. Portanto a legitimidade do Sistema do Tratado Antártico tem como fundamento outros elementos para além da democracia. Para Moravcsik (2004), não se pode avaliar a legitimidade democrática de uma instituição de governança global apenas por seu caráter normativo e sim por sua aplicabilidade nas instituições políticas reais. Para Dahl (1999), organizações internacionais jamais poderão ser consideradas democráticas, pois a questão da escala de um eleitorado internacional e mesmo a distância percebida pelo grande público com relação à possibilidade de intervenção no processo decisório inviabilizam a democracia no âmbito da governança global.

Assim, para Buchanan e Keohane (2006), a legitimidade em instituições internacionais se fundamentaria exteriormente a elas. Os atores externos epistêmicos seriam aqueles atores que compartilhariam razões morais com as instituições internacionais e apoiariam sua atuação. A continuidade deste apoio apenas se daria por meio do reconhecimento de sua integridade institucional, ou seja, essas instituições atuariam em conformidade com os propósitos de sua criação, apresentando valores epistêmicos. Dessa forma, as instituições internacionais prestariam conta (accountability) de sua atuação aos atores epistêmicos e estes à sociedade civil transnacional, garantindo, então, o processo de legitimação.

Portanto, a consolidação do Sistema do Tratado Antártico pode ser entendida por meio da atuação de atores externos epistêmicos que legitimam seu arranjo institucional independentemente da existência de mecanismos democráticos de participação, representação e deliberação em seu funcionamento. 


\section{Antártica: da descoberta ao Sistema do Tratado Antártico (STA)}

Desde a sua descoberta (ver Figura 1), a Antártica tornou-se uma região de grande interesse para a sociedade internacional por meio de inúmeras incursões ao continente, oriundas dos mais diversos Estados. Nas primeiras décadas, as principais atividades eram a exploração de peles de focas e de óleo de elefante, com a presença dos EUA, Grã-Bretanha, França, Austrália, Nova Zelândia e Noruega. Posteriormente, várias expedições nacionais foram realizadas com o propósito de melhor conhecer o funcionamento natural antártico, a potencialidade de seus recursos e também para garantir a presença política na região. Este momento é conhecido como "Era Heroica", quando a Antártica experimentou uma intensa atividade humana (HOWKINS, 2008). Contudo, a presença de tantos Estados diferentes (quando não rivais) levou a disputas e demandas por soberania, de modo a garantir o acesso permanente das mesmas à exploração da Antártica.

Figura 1: linha do tempo com os principais eventos históricos na região Antártica

\begin{tabular}{|c|c|c|c|c|c|}
\hline $\begin{array}{c}\text { Viagens } \\
\text { marítimas } \\
\text { 1772-1775: Capitão } \\
\text { Cook atravessou } \\
\text { duas vezes o } \\
\text { círculo Antártico } \\
\text { (Paralelo } 60^{\circ} \text {. }\end{array}$ & \multicolumn{2}{|c|}{$\begin{array}{c}\text { Era Heroica: Explorações } \\
\text { Científicas } \\
\text { 1898-1940: Os estudos focavam-se } \\
\text { em zoologia, meteorologia, } \\
\text { geologia e eram oriundos da } \\
\text { Bélgica, Grã-Bretanha, França, } \\
\text { Alemanha, Escócia, Austrália, } \\
\text { Suécia, Noruega e Japão. }\end{array}$} & \multicolumn{2}{|c|}{$\begin{array}{c}\text { Declaração } \\
\text { Escudero } \\
\text { 1948: prospecção } \\
\text { para uma atividade } \\
\text { cooperativa na } \\
\text { Antártica, sugerida } \\
\text { pelo Chile }\end{array}$} & $\begin{array}{c}\text { Ano Geofísico } \\
\text { Internacional (AGI) } \\
\text { 1957-1958: os mesmos } \\
\text { Estados da Conferência de } \\
\text { Paris apresentaram suas } \\
\text { atividades científicas, } \\
\text { implementando uma } \\
\text { motivação para a } \\
\text { cooperação internacional } \\
\text { na região. }\end{array}$ \\
\hline $\begin{array}{c}\text { Interesse comercial e de } \\
\text { exploração } \\
\text { 1798-1898: Peles de foca e } \\
\text { óleo de elefante-marinho. } \\
\text { Expedições oriundas dos: } \\
\text { EUA, Grã-Bretanha, } \\
\text { Austrália, Nova Zelândia, } \\
\text { Noruega, França e } \\
\text { Argentina. }\end{array}$ & $\begin{array}{c}\text { Descoberta do } \\
\text { Continente } \\
\text { (1820): diferentes } \\
\text { reivindicações: } \\
\text { Thaddeus } \\
\text { Bellingshausen } \\
\text { (Rússia); Nathaniel } \\
\text { Palmer (EUA) e Edward } \\
\text { Bransfield William } \\
\text { Smith (Reino Unido). }\end{array}$ & $\begin{array}{r}\text { Demandas } \\
\text { soberan } \\
\text { Argentina, AL } \\
\text { Chile, França, I } \\
\text { Nova Zelândia } \\
\text { Unido (em o } \\
\text { alfabétic }\end{array}$ & $\begin{array}{l}\text { por } \\
\text { ia } \\
\text { strália, } \\
\text { Joruega, } \\
\text { e Reino } \\
\text { rdem } \\
\text { a). }\end{array}$ & $\begin{array}{r}\text { Conf } \\
\text { 1955: o } \\
\text { internacic } \\
\text { como pri } \\
\text { do Sul, A } \\
\text { Bélgica, } \\
\text { Inglat } \\
\text { Zelând }\end{array}$ & $\begin{array}{l}\text { encia de Paris } \\
\text { meiro encontro } \\
\text { a com a Antártica } \\
\text { pal tópico. África } \\
\text { entina, Austrália, } \\
\text { ile, EUA, França, } \\
\text { a, Japão, Nova } \\
\text { URSS fizeram } \\
\text { parte. }\end{array}$ \\
\hline
\end{tabular}

Fonte: Elaboração própria baseado em BECK,1986; FUCHS, 1983.

A reivindicação por soberania territorial na Antártica tende a ser uma questão inevitavelmente delicada e complexa, pois envolve desde Estados que iniciaram atividades soberanas por meio de contratos privados de exploração e comércio em algumas ilhas (o caso da França, por exemplo, ao anexar as ilhas Kerguelen e firmar um contrato privado de exploração, em 1893); até declarações oficiais de soberania, tornando uma única marcação temporal um tanto arbitrária. Ademais, algumas dessas reivindicações foram realizadas de forma progressiva, localizando-se inicialmente fora da região Antártica (ao norte do paralelo 60 sul) e, ao longo dos anos, se estendendo para a Antártica em si. De um modo geral, pode-se afirmar que as reivindicações por soberania territorial ocorreram entre a primeira década do século XX até a 
$2^{a}$ Guerra Mundial e, inevitavelmente, configurou algumas superposições de fronteira na região (FUCHS, 1983).

Após o fim da $2^{\text {a }}$ Guerra Mundial e o despontamento dos EUA e da URSS como as superpotências do pós-guerra, observa-se uma mudança no tratamento da questão Antártica. Nem os Estados Unidos, tampouco a União Soviética, estabeleceram demandas territoriais. Mas isso não significou que estes países não tivessem uma política específica para o continente. Em 1946/47, os EUA realizaram a maior expedição antártica já organizada, que incluía muitos dispositivos de mapeamento da região e não reconheciam como legítimas quaisquer reivindicações de soberania por territórios não habitados (VIEIRA, 2006). Ao mesmo tempo, a União Soviética celebrou o "Dia Antártico" em Moscou, em 1949. No ano subsequente, o governo soviético declarou o seu não reconhecimento a qualquer tratado que viesse a ser estabelecido sobre a Antártica sem a sua presença (FUCHS, 1983).

Assim, as diversas demandas por soberania acrescidas do posicionamento político das duas superpotências tornaram a Antártica uma região extremamente relevante para a paz e segurança internacional, pois seu frágil ecossistema, sua localização estratégica', sua abundância em recursos naturais (incluindo sua potencialidade para recursos minerais) e a ausência de uma presença humana permanente fizeram do continente um ponto de extrema relevância para a agenda política das principais potências da sociedade internacional. E esperava-se uma intensificação das tensões na região. Contudo, a indefinição com relação às reivindicações territoriais na Antártica reforçou uma orientação de natureza cooperativa entre os países, levando a um processo de normatização da atuação humana no território (VICUÑA, 1988).

O despertar cooperativo na Antártica veio com a Declaração Escudero² que propunha a suspensão temporária das reivindicações por soberania em prol de uma atuação cooperada na região. Mas a definição sobre como seria a atuação dos países na região permanecia em aberto. Assim, buscou-se na atividade científica a via que incitasse as primeiras normatizações para a atuação dos países no continente. No Ano Ceofísico Internacional de 1957-58, a questão da atividade científica na Antártica foi abordada, reunindo diversos Estados que tinham alguma forma de envolvimento com o continente. A partir deste evento, estabeleceu-se a importância da pesquisa científica antártica, levando à formação da primeira base para discussões sobre um futuro tratado, já que todos os requerentes por soberania decidiram permitir livre acesso à pesquisa científica no continente.

Em 1959, os doze Estados que fizeram parte do Ano Geofísico Internacional, dentre eles os EUA, foram convidados por esse último a assinar o Tratado Antártico em Washington D.C., que passou a ter validade a partir de 1961. Os signatários eram compostos por todos os Estados reivindicantes de soberania mais aqueles que já mantinham alguma atividade na região (África do Sul, Bélgica, EUA, Japão e URSS). O Tratado foi formulado com o objetivo de estimular um ambiente internacional cooperativo para a região, fundamentando-se em uma orientação pacífica e que buscava afastar a região de se tornar um objeto de disputa e conflito internacionais.

1 O Oceano Clacial Antártico tem interfaces com os oceanos Atlântico, Índico e Pacífico (VIEIRA, 2006, p. 52).

2 Julio Escudero Guzmán, conselheiro da chancelaria chilena, elaborou o Plano Escudero em 1948 em que propunha, como solução provisória para o impasse na Antártica, a suspensão das reivindicações por soberania por 5 a 10 anos. (SANCHEZ, 2007, p. 130). 
A orientação pacífica do Tratado foi traduzida por uma permanente proibição de estabelecimento de bases militares, de realização de testes nucleares e de descarte de materiais radioativos. Contudo, o Tratado não estabeleceu uma solução para o problema da exploração de recursos na região, pois a exploração poderia comprometer não só a preservação, como prejudicar a promoção da cooperação entre os Estados membros, despertando também disputas com atores externos ao arranjo.

Assim o Tratado Antártico foi considerado eficaz ao "congelar" as demandas por soberania em prol da atividade científica, criando diversas colaborações entre os projetos nacionais de atuação no continente. A manutenção de um objetivo pacífico levou à permanência do Tratado e a adesão de novos membros. A partir dos anos 1980, com o crescimento do número de membros, criou-se uma divisão através das categorias de consultivos e não consultivos, onde os primeiros eram compostos pelos signatários originais mais aqueles membros que conseguissem comprovar substancial atividade científica na região, detendo poder de voto e veto sobre as ações no continente (FERREIRA, 2009)3.

O Tratado Antártico de 1959 focava na preservação de um ambiente pacífico e cooperativo, estabelecendo um arranjo de regras e normas com relação a decisões e participações nas atividades antárticas entre os signatários. E o Tratado evoluiu. Ao longo dos anos, foram adicionadas as resoluções provenientes dos Encontros das Partes Consultivas (Antarctic Treaty Consultative Meetings ATCM)4; a Convenção para a Conservação das Focas Antárticas (CCAS, Londres, 1972); a Convenção para a Conservação dos Recursos da Vida Marinha Antártica (CCAMLR, Camberra, 1980); o Protocolo de Proteção Ambiental (Madri, 1991), além das decisões vindas das Reuniões Consultivas Especiais e das Reuniões de Especialistas 5 .

Todas essas adições ocorreram a partir dos Encontros Consultivos que buscaram realizar os ajustes necessários para o melhor desempenho do acordo, provendo a sua permanência e sua contínua legitimação. Os Encontros Consultivos basearam-se em um ambiente de formulação de regras que permitiam o desenvolvimento de um arranjo jurídico, resultando na institucionalização do Tratado Antártico. Robert Guyer (Fuchs, 1983) denominou este processo de consolidação da normatização das práticas antárticas em Sistema do Tratado Antártico (STA), apresentando-se como uma forma de regime mais legitimado.

As diferenças entre o Tratado em si e o Sistema do Tratado podem ser observadas por meio de dois padrões de ação estabelecidos entre os membros. Durante os primeiros anos do Tratado, as resoluções dos problemas eram propostas em função das requisições das partes, que demandavam soluções rápidas e urgentes. Problemas como liberdade na pesquisa científica, desmilitarização da região, exclusividade dos fins pacíficos, congelamento das demandas por soberania e consolidação do sistema consultivo eram percebidas como urgentes a partir do momento em que o Tratado tornou-se válido. Somente a partir do alcance destas ações é

3 Na prática, tornar-se um membro consultivo significava o envio de missões científicas e a manutenção de uma estação permanente na região antártica. (FERREIRA, 2009, p. 54).

4 Os Encontros Consultivos normatizaram as atividades dos membros via a formulação de medidas, resoluções, decisões e recomendações, onde a aceitação das normas tornou-se condição tanto para a admissão de novos membros quanto para a aquisição do status consultivo.

5 A Convenção para a Regulação de Atividades sobre Recursos Minerais Antárticos (CRAMRA, Wellington 1988) não foi ratificada por nenhum país, contudo, teve um papel fundamental para referenciar os objetivos do Protocolo de Proteção Ambiental de Madri, 1991. 
que se promoveram ações cooperativas efetivas e de longo prazo entre os países membros, principalmente por meio do Comitê Científico de Pesquisa Antártica (SCAR), do Comitê para Proteção Ambiental $(C E P)^{6}$ e do Conselho de Cestores dos Programas Nacionais Antárticos (COMNAP) ${ }^{7}$, que auxiliam na definição da agenda do STA.

Assim que o sistema cooperativo se institucionalizou, os Encontros Consultivos, comitês e conselhos passaram a ser percebidos também como arenas próprias para antecipação de potenciais problemas que pudessem vir a surgir na Antártica. Este é o caso da exploração de recursos na região. As discussões sobre exploração de recursos foram adiadas ao máximo, especialmente nos primeiros anos do Tratado, uma vez que questões e disputas poderiam ser levantadas entre as partes, bem como entre as não partes, inviabilizando a legitimação do Tratado e a sua eficiência em produzir cooperação. Posteriormente, já no STA, tentou-se ratificar sem sucesso uma convenção que normalizasse a exploração e o comércio de recursos minerais na região, resultando na sua proibição pelo Protocolo de Proteção Ambiental de 1991.

Assim, a transformação do Tratado Antártico em Sistema do Tratado Antártico também pode ser observada por meio dos problemas surgidos a partir do próprio arranjo cooperativo criado. Inicialmente, o Tratado atuava de forma mais passiva com relação às demandas encaminhadas para serem normatizadas. A não interferência ou a garantia da livre pesquisa científica e a desmilitarização da região eram práticas que não causavam complicações para as distinções entre membros e não membros do Tratado Antártico, pois a aplicação era indistinta.

Entretanto, quando o Tratado se institucionaliza a ponto de se tornar um sistema (STA), surgem novas questões tão complexas quanto seu sistema de convenções, medidas, decisões, resoluções e recomendações. O exemplo mais contundente é a questão da política de exploração de recursos que sensibilizou as distinções entre signatários e não signatários, e mesmo entre membros consultivos e não consultivos. Regularizar a exploração de recursos na Antártica demandava resoluções quanto à definição jurídica da região e, consequentemente, quanto à destinação dos dividendos dessas atividades. Consequentemente, a natureza da vinculação com a Antártica, que qualificaria ou não um direito à exploração, tornava-se um elemento essencial nesta discussão.

As partes passaram a agir, portanto, sobre uma estrutura cada vez mais complexa de obrigações e práticas, o que dificultava a manutenção da cooperação. Acomodações internas foram feitas para manter o equilíbrio entre as partes, evitando debates sobre os tópicos mais sensiveis e contestados (como, por exemplo, a normatização da exploração de recursos). Por outro lado, as acomodações externas buscavam conciliar os diversos interesses antárticos, incluindo aqueles externos ao Tratado, visando manter a legitimidade do arranjo perante esses atores (VICUÑA, 1988).

6 Criado a partir do Protocolo de Madri de 1991.

7 Criado a partir do Protocolo de Madri de 1991 


\section{Sistema do Tratado Antártico e os questionamentos sobre seu déficit democrático}

Figura 2: Diagrama das problematizações identificadas no STA

\begin{tabular}{|c|c|}
\hline \multicolumn{2}{|c|}{ Problematizações do STA } \\
\hline Internas ao Tratado & Externas ao Tratado \\
\hline Relações hierárquicas entre os membros & $\begin{array}{c}\text { Reconhecimento e legitimação do STA pela } \\
\text { sociedade internacional }\end{array}$ \\
\hline $\begin{array}{l}\text { Estabelecimento da fronteira entre o escopo } \\
\text { das ações do STA e dos agentes individuais }\end{array}$ & \\
\hline
\end{tabular}

Fonte: Elaboração própria baseado em VICUÑA, 1988)

A origem das contestações ao Sistema do Tratado Antártico baseia-se nas problematizações que surgem interna e externamente ao arranjo normativo do Tratado. Os problemas internos derivam do estabelecimento de diferenças hierárquicas internas ao tratado, devido às distinções entre membros "consultivos" e "não consultivos". Os direitos e as obrigações diferem muito entre os dois, pois são as atividades das partes consultivas que fundamentam as atividades do Tratado Antártico, uma vez que cabe a elas o estabelecimento das diretrizes de ação e a conferência do status "consultivo" a outros membros. Assim, de uma maneira geral, o processo de tomada de decisão que envolve as atividades antárticas é exclusivo aos Estados-membros consultivos. Além disso, o compartilhamento das descobertas científicas, os relatórios científicos, a participação nos encontros e o respectivo direito de voto, além do envio de pessoal a missões, eram também atividades de caráter seleto.

Internamente também há divergência quanto à autonomia das atividades dos Estados, pois o STA deteria a quase total determinação sobre as ações dos Estados signatários no continente. Essa hierarquização interna se deu porque, na origem do Tratado, foram aceitos aqueles Estados que demonstraram de fato algum interesse pelo continente, considerando tanto aqueles que fizeram incursões científicas e comerciais, quanto aqueles reivindicadores de soberania territorial. A adesão de novos membros, ao longo do tempo, estabeleceu uma hierarquia com relação aos primeiros signatários, e as distinções de status visavam garantir a manutenção do controle do STA pelos últimos.

Externamente, a ideia de que o regime adotado necessite levar em conta não só a posição dos membros consultivos, mas também o interesse de outros países e da sociedade internacional como um todo, denomina o processo de "acomodação externa". Ela busca reconciliar os interesses existentes tanto interna quanto externamente ao tratado por meio de novos mecanismos de participação. Esse processo é considerado essencial para garantir a aceitação internacional do regime a ser adotado na Antártica.

Porém essa legitimidade jamais foi conferida de forma unânime e acrítica. As limitações à participação são o principal alvo de críticas da sociedade internacional ao Tratado, mas são justificadas pelos membros devido à excepcionalidade da Antártica. A severidade e a hostilidade do ambiente antártico, somadas às tensões políticas subjacentes à presença humana na 
região acarretam uma maior complexidade do regime. O Sistema do Tratado Antártico, na busca por manter a estabilidade do Tratado e a proteção ambiental da região, estabeleceu critérios de seleção para a manutenção de um controle sobre os Estados e a natureza de suas ações na região. Para atuar no continente, exige-se sólida capacidade técnica e científica dos ingressantes, pois falhas nas atividades antárticas poderiam ter consequências catastróficas. Desta forma, as ações devem ser baseadas em sólida experiência científica e logística e não com base em improvisação (VICUÑA, 1988).

O Tratado Antártico era caracterizado por uma participação limitada, já que certos critérios deveriam ser satisfeitos para se obter o status consultivo. Este procedimento foi elaborado para se evitar que o Sistema do Tratado fosse varrido por visões de governos desinformados a respeito das práticas antárticas, embora também contribuiu para assegurar a predominância dos doze signatários originais dada a inevitável natureza seletiva de um agrupamento baseado no critério da expertise. (BECK, 1986, p. 187, tradução nossa). ${ }^{8}$

Em 1983, o Chile elaborou o documento "Operação do Tratado Antártico" questionando a posição dos terceiros estados, até então completamente excluídos do sistema. A proposta era de que esses também recebessem o Relatório Final e as Recomendações dos Encontros Consultivos, tendo acesso às informações científicas e participando desses mesmos encontros como observadores. Foi também por insistência chilena que critérios específicos para a ascensão a membro consultivo foram estabelecidos. (BECK, 1986)

O objetivo desses esforços era garantir uma maior transparência das atividades do Sistema do Tratado Antártico, o que levaria à sua maior legitimidade internacional. Além disso, o estabelecimento de critérios não buscou fortalecer uma discriminação entre os signatários do Tratado, mas sim garantir que as ações sob o Tratado de fato envolvessem somente aqueles realmente interessados e envolvidos no continente, abrindo a possibilidade de se tornarem membros consultivos e participarem ativamente dos encontros (VICUÑA, 1988).

Contudo, a maior participação dos Estados não implicou na redução da participação dos membros consultivos, pois quanto mais Estados aderiam ao Tratado, mais se consolidava a diferença entre os status consultivos. No início, o critério de aceitação de novos signatários era incondicional, onde qualquer Estado membro das Nações Unidas poderia demandar acesso ao Tratado. Porém, simultaneamente, um segundo critério mais restritivo foi adotado, onde um Estado não membro só poderia participar dos Encontros das Partes Consultivas com convite e com consentimento dos outros membros consultivos.

Portanto, ao mesmo tempo em que o STA buscava ampliar a participação de Estados na busca por uma maior legitimidade internacional, ele também fortalecia o controle hierárquico sobre a atuação no continente, uma vez que cada novo membro era obrigado a aquiescer a todo o sistema de normas já estabelecido pelos primeiros Estados. Assim, o processo de admissão, por mais que se ampliasse, foi mantido de forma gradual para que não se corrompesse os

8 The Antarctic Treaty was characterized by limited participation, since certain criteria had to be satisfied for the attainment of Consultative Party status. This procedure was designed to prevent the treaty system being swamped by the views of government uninformed about Antarctic practicalities, although it served also to ensure the continued predominance of the original twelve signatories on account of the inevitably select nature of a grouping based upon specialized criteria. 
princípios fundamentais que regiam as atividades antárticas. Por isso a ideia de que um membro se tornasse automaticamente um membro consultivo nunca foi bem aceita.

Contudo, o debate se acirrou com relação à participação de atores externos no STA. Após a $2^{a}$ Guerra Mundial, a Índia como representante dos Estados não alinhados questionava o exclusivismo do Tratado. Porém, pouco tempo depois ela se torna um membro signatário e consultivo, corroborando o arranjo normativo existente (BECK, 1986, p. 192). Já o primeiroministro malaio, em 1982, recolocou a questão da participação das Nações Unidas no Tratado durante a Assembleia Geral. Para ele, o Tratado Antártico era uma forma de neocolonialismo que não refletia os verdadeiros sentimentos dos membros das Nações Unidas. Ele também afirmou que todos os Estados reivindicantes deveriam abrir mão de suas demandas por soberania para que a ONU administrasse a região, ou que os principais atuantes se colocassem como os portadores de todas as nações do mundo. Os próprios membros de agências especializadas da ONU passaram a demandar acesso irrestrito aos Encontros Consultivos (VICUÑA, 1988).

Considerando a múltipla importância da Antártica e seu interesse para a humanidade, a ONU definiu a região como um patrimônio comum que deveria ser governado por um regime internacional que preservasse a paz e a segurança internacional, facilitasse a pesquisa científica e o seu intercâmbio, garantisse a preservação ambiental e, se houvesse a exploração de recursos, que seus dividendos fossem compartilhados equitativamente. Logo, qualquer regime antártico a ser estabelecido deveria contar com a participação dos Estados-membros da ONU, bem como de suas agências especializadas e de outras organizações internacionais, devendo o regime ser passivel de revisão pela própria ONU, pois esta constituiria a organização internacional mais representativa (ZAIN-AZRAAI, 2008).

Assim, o questionamento da democratização e da legitimidade do STA fundamentase nessas duas problemáticas: a hierarquia interna e a seletividade externa. 0 atual regime antártico, quando analisado, cumpre de fato com seus objetivos essenciais: ele prega a não militarização e a não nuclearização, exige inspeções in loco, e promove a pesquisa científica e a proteção ambiental. Porém, o regime falha na distribuição de poder interno, no envolvimento de novos atores e na possibilidade de sua revisão pela sociedade internacional. Os membros do Sistema do Tratado Antártico possuem o direito exclusivo de tomar decisões e regular as atividades, sem qualquer accountability9 ${ }^{9}$. Internamente, não há sistematização de critérios de peso ou votos ponderados. As tomadas de decisão pelos Estados consultivos são totais, exclusivas e não revisáveis. E num ambiente internacional de crescente democratização, a hierarquia e a exclusividade da Antártica se colocam de forma paradoxal (ZAIN-AZRAAI, 2008).

Essa hierarquia e exclusividade são geralmente justificadas pelos critérios da experiência e expertise, onde a complexidade do ambiente antártico exigiria uma qualificação daqueles que agem e decidem por ela. Porém, no mundo atual, as discussões e envolvimentos nos assuntos internacionais são também justificados pelo interesse comum e não somente pela expertise dos países. 0 critério de expertise impediria o desenvolvimento do movimento de democratização

9 Accountability é entendido aqui como mais uma etapa do processo de representação democrática, quando o representante autorizado necessita "prestar contas" de suas ações para o representado, garantindo assim uma forma de controle democrático sobre a ação política e, consequentemente, a legitimidade da mesma. Ver AVRITZER, 2007 e LAVALLE, HOUTZAGER e CASTELLO (2005). 
dos assuntos internacionais na sociedade internacional, por mais que ela ainda não seja absoluta de fato. Assim, a questão em voga é a elaboração de um arranjo que consiga ser mais democrático, acomodando os diversos interesses sobre a Antártica (ZAIN-AZRAAI, 2008).

\section{A democracia em organizações internacionais de governança global}

O debate referente a uma maior democratização do Sistema do Tratado Antártico pode ser melhor entendido por meio das discussões referentes ao déficit democrático em instituições internacionais de governança global. Diversos problemas e desafios postos à sociedade internacional perpassam fronteiras nacionais e demandam soluções baseadas em decisões coletivas que, em geral, implicam desacordo quanto ao seu resultado ótimo e aos critérios justos de distribuição dos seus custos. Assim, tornam-se necessários meios que possibilitem a tomada de decisão coletiva, facilitando o acesso à informação e criando um ambiente de confiança, onde indivíduos e Estados formulem decisões conjuntas que considerem válidas e efetivamente as adotem (CHRISTIANO, 2011).

Esse é um dos princípios sobre os quais se formam as instituições internacionais de governança global. Elas podem variar quanto ao seu grau de institucionalização, podendo ser desde regimes internacionais, que regulem uma questão específica e demandem a coordenação das ações de determinados atores internacionais, a organizações internacionais em si, com alto grau de institucionalização e uma burocracia própria que atue nas atividades de funcionamento dessas instituições. Por outro lado, elas também podem surgir de um consentimento entre Estados, como também podem se configurar como associações voluntárias e de caráter cosmopolita, cuja atuação está para além do assentimento dos Estados e de suas estruturas políticas domésticas.

Todavia, independentemente das particularidades encontradas na conformação dessas instituições, a questão da legitimidade de suas ações é um ponto sensivel tanto para a teoria política em si, quanto para o ambiente institucional no qual atuam. Assim, entendendo a legitimidade como o direito reconhecido de se regular um conjunto de questões (CHRISTIANO, 2011), a legitimidade institucional adquire a função moral de tornar suas decisões como reconhecidamente válidas, levando os atores envolvidos a adotá-las.

Christiano (2011) afirma que, segundo o pensamento político moderno, a legitimidade conferida a um processo decisório de autoridade perpassa três critérios: a qualidade dos resultados desse processo decisório; o consentimento de seus membros; e a base da tomada de decisão em processos liberais-democráticos. Ao passo que esses critérios, quando conferidos a uma instituição internacional de governança global, passam a ser entendidos como: decisões que apresentem padrões mínimos de moralidade; princípio justo de associação voluntária; e o princípio de democracia.

Dryzek (1996, p. 4) define a democracia como um concurso de várias ideias, posições, opiniões, argumentos, críticas, modelos e teorias. Esse concurso pertenceria a uma construção, distribuição, aplicação e limitação coletiva da autoridade política; e sua orientação fundamental seria se tornar cada vez mais democrático. Isso não significaria apenas a extensão da democracia 
para outras sociedades, mas essencialmente seu aprofundamento. E este é o ponto central da problemática das instituições internacionais: como basear sua legitimidade em critérios democráticos quando se trata de problemas e processos decisórios baseados para além do Estado? A democracia poderia ser estendida também para o âmbito global e suas instituições?

Para alguns autores (HELD, 2004) esse movimento de expansão e aprofundamento democrático seria inevitável, uma vez que a provisão de bens públicos globais requereria o desenvolvimento de mecanismos democráticos, tais como transparência procedimental e accountability (prestação de contas), para que suas instituições internacionais possam se manter e serem efetivas segundo os propósitos pelos quais foram criadas. Contudo, para Moravcsik (2004), avaliações sobre a legitimidade democrática de instituições internacionais podem se tornar um exercício utópico quando a base comparativa é dada por sistemas democráticos ideais, que não são encontrados na realidade.

Sistemas democráticos reais (as democracias avançadas da atualidade como o melhor dos exemplos) não se apresentam como democracias perfeitas normativamente, pois enfrentam constantes desafios a seu funcionamento tais como: informação pública limitada, interesses particularistas, arranjos regulatórios limitantes, credibilidade nos compromissos e consenso limitados entre os atores. Esses desafios são remediados, mas não solucionados, portanto guardam certa distância de um ideal democrático tanto quanto as instituições internacionais. E se, empiricamente, as instituições internacionais têm performances legitimadas, muitas vezes suplantando a atuação dos sistemas nacionais, as críticas a seu déficit democrático poderiam ter o privilégio da dúvida (MORAVCSIK, 2004), não sendo este considerado um agravante à existência, legitimidade e eficiência de suas práticas em termos de seus propósitos.

Assim, as discussões sobre a coerência filosófica da democracia, ou seja, a democracia normativamente embasada e aplicável, baseiam-se em quatro tradições: libertária, pluralista, social-democrática e deliberativa (MORAVCSIK, 2004). A concepção libertária fundamenta-se na proteção das liberdades individuais frente à potencialidade de arbitrariedade do poder do Estado. Consequentemente, as instituições internacionais de governança global seriam vistas como pouco atentas aos interesses individuais e seus reguladores agiriam de forma arbitrária e autointeressada na maioria das vezes. Já a concepção pluralista entende que a democracia legítima é aquela que permite aos indivíduos influenciar de forma igual e significativa os resultados políticos. Entretanto, no que tange às instituições internacionais, pluralistas entenderiam que a escala e a distância com relação ao eleitorado impossibilitariam essa legitimidade.

Já os sociais-democratas entenderiam a democracia como o meio de atenuar os efeitos negativos da concentração de poder trazidos pelas economias capitalistas, devendo manter o equilíbrio entre liberalização do mercado e proteção social. Contudo, instituições internacionais tenderiam a incorporar os vieses neoliberais na formulação das políticas. Países mais ricos teriam maior poder de barganha no processo decisório e a agenda seria composta segundo os principais interesses desse grupo.

E, por fim, os deliberativos entenderiam a democracia como o meio de assegurar a participação igualitária, atenuar vieses existentes e, principalmente, aprimorar a capacidade política dos cidadãos. Mais importante que a participação em si, é que esta seja significativa e efetiva. Por isso as instituições internacionais são vistas com desconfiança: não importa quão 
formalmente democrática elas sejam - se há passividade política dos cidadãos não é possível que se tenha deliberação pública significativa, consequentemente, legitimidade democrática.

Se o Sistema do Tratado Antártico for avaliado de forma somente normativa, todas essas limitações anunciadas pelas diferentes concepções democráticas podem ser encontradas. A crítica feita pelas Nações Unidas e por Estados não signatários do Tratado é de que os membros consultivos formulam normas e atuam na Antártica unicamente baseados em seus próprios interesses, portanto de forma arbitrária. E a tomada de decisão não tem uma sustentação democrática, pois se fundamenta somente na capacidade técnica que eles próprios se aferem, excluindo os membros não consultivos e quaisquer outros atores externos da decisão.

A própria origem do Tratado Antártico, que contou com 12 primeiros signatários, foi baseada na demonstração de alguma forma de atividade anterior no continente, ou seja, quem primeiramente estava lá. Portanto, a crítica feita por Estados africanos, que acusam sua exclusão do STA por não serem Estados soberanos na época de sua criação (BECK, 1986), corrobora a visão dos sociais-democratas. Principalmente, como as decisões se concentram nas mãos dos membros consultivos, a sociedade internacional é, de um modo geral, afastada das decisões e das atividades que ocorrem na Antártica.

Para Moravcsik (2004), a avaliação do déficit democrático deve levar em conta não só a coerência filosófica, mas também a viabilidade pragmática. A participação irrestrita na tomada de decisão seria a melhor opção num mundo ideal de sistemas políticos democráticos perfeitamente participativos, igualitários e deliberativos. Entretanto, no mundo real, a melhor opção torna-se a delegação, pois os custos transacionais dos cidadãos na sua participação política não podem ser ignorados. Logo, a maneira como sistemas constitucionais lidam com tais imperfeições democráticas é isolando os tomadores de decisão com relação às disputas entre grupos de interesse, por meio da delegação da autoridade política.

No caso da Antártica, esse isolamento da tomada de decisão e a consequente delegação da autoridade política são muito mais evidentes. Não somente outros atores como Estados não signatários, Nações Unidas ou mesmo organizações não-governamentais estão afastados do processo decisório em si: o próprio cidadão comum não participa dos desdobramentos normativos da região. 0 cidadão comum não vive rotineiramente as questões antárticas e tampouco conhece suas especificidades a ponto de estar apto a se posicionar com relação às decisões do STA. Dessa forma, ele não influencia a formulação da política antártica do seu Estado nem mesmo atua diretamente no âmbito decisório do Tratado. Como consequência, a fragilidade e o desconhecimento sobre o funcionamento do ecossistema antártico embasam o argumento da necessidade de expertise e de delegação das decisões para os membros consultivos.

Assim, o processo de delegação da tomada de decisão no âmbito das organizações internacionais de governança global ocorre em razão de três circunstâncias estruturais: (i) complexidade social e o papel da expertise; (ii) incerteza política e o papel dos direitos; e (iii) diferenças subjacentes no poder social e o papel das ligações (MORAVCSIK, 2004). Como visto acima, no caso da complexidade social e o papel da expertise, delega-se a tomada de decisão daquilo que requer maior expertise. Logo, a institucionalização das normas para participação no Sistema do Tratado Antártico foi feita por um grupo restrito de tomadores de decisão fundamentados no gradiente de conhecimento e pesquisa científica realizados na região. 
Com relação à circunstância de incerteza política e o papel dos direitos, os cidadãos tendem a favorecer as políticas que reduzam os riscos de perdas individuais num futuro incerto, e a defesa dos direitos básicos torna-se mais importante que a participação na deliberação dos mesmos. No caso, a Antártica nunca apresentou uma presença humana permanente, portanto nunca fez parte das preocupações imediatas de qualquer cidadão comum. As incursões no continente sempre foram de caráter temporário, portanto a exclusividade das decisões para aqueles que de fato têm competência para tomá-las é vista de forma mais segura que outro arranjo. Já para aqueles Estados mais geograficamente próximos (Chile e Argentina), a Antártica faz parte do imaginário coletivo nacional, portanto defende-se a atuação do país na região, mas não a participação e deliberação diretas sobre as regras e normas que a governam.

Por fim, na circunstância das diferenças subjacentes no poder social e o papel das ligações, busca-se o empoderamento das burocracias (domésticas ou internacionais) das organizações internacionais para evitar que interesses particulares prevaleçam sobre os interesses muitas vezes difusos da maioria. Em disputas políticas entre grupos de interesses, aqueles mais organizados tendem a melhor controlar os desdobramentos dos processos decisórios. Portanto a delegação da autoridade política a um grupo técnico buscaria garantir que uma maioria não organizada não seja prejudicada pela atuação de interesses particulares melhor organizados. No caso antártico, a não ratificação da Convenção para a Regulação de Atividades sobre Recursos Minerais Antárticos (CRAMRA, Wellington 1988) demonstra que os interesses particulares de empresas mineradoras que pressionavam para a abertura e regulação da exploração mineral na Antártica não prevaleceram sobre o consenso geral de se preservar ambientalmente o continente.

Dadas essas três circunstâncias estruturais, Moravcsik afirma que "estruturas de autoridade da governança global mais isoladas e delegadas podem ser pensadas como mais 'representativas' das preocupações dos cidadãos, precisamente porque são menos diretamente democráticas" (MORAVCSIK, 2004, p. 347, tradução nossa)10. Para o autor, a viabilidade pragmática é fundamental para se pensar a forma mais eficiente de representação dos interesses dos cidadãos nas organizações internacionais. A forte especialização dos aspectos da governança democrática requer uma menor participação política direta e o isolamento se dá na tentativa de garantir legitimidade às decisões, dado o desconhecimento com relação ao tema e a dificuldade dos cidadãos em formular um posicionamento que se desdobre numa demanda por participação e deliberação nessas instâncias. As delegações tornariam críveis os compromissos firmados e inibiria o poder de interesses particulares no processo decisório.

E, finalmente, Moravcsik ressalta que se a democracia for muito exigida no âmbito das organizações internacionais, sempre haverá a opção do unilateralismo (a retirada de grupos de uma ação coletiva). Para um arranjo normativo como o Sistema do Tratado Antártico, baseado na suspensão comum das reivindicações por soberania e na promoção da pesquisa científica em um ambiente fundamentado na paz e na cooperação internacional, democratizar o processo decisório poderia levar à saída das grandes potências (no caso dos EUA, que lideraram a formulação do tratado), além de incitar a volta das demandas por soberania territorial

10 "more insulated and delegated authority of global governance structures might be thought as more 'representative' of citizen concerns precisely because they are less directly 'democratic'." 
dos Estados reivindicantes, ocasionando a escalada da tensão na região. Isso é fortemente demonstrável, pois são esses mesmos Estados que rejeitam as demandas por uma participação ativa das Nações Unidas e de suas agências no sistema.

Diferentemente da visão apresentada por Moravcsik, Robert Dahl (1999) não entende que organizações internacionais possam ser consideradas pragmaticamente democráticas. Para o autor, organizações democráticas não são e jamais serão democráticas. Para justificar sua posição, Dahl se fundamenta em dois aspectos do exercício da democracia dentre os inúmeros existentes: democracia como um sistema de controle popular sobre decisões e políticas governamentais; e democracia como um sistema de direitos fundamentais.

No primeiro caso, a democracia é entendida como um governo que é responsivo e presta contas a demos. Há uma autoridade soberana que decide sobre questões políticas de forma direta ou representativa (via eleições). Para que isso ocorra, é necessário um conjunto de direitos que possibilitem esse controle da população sobre as decisões e as políticas. Ao passo que, no segundo caso, a democracia se apresenta como um sistema que provê direitos fundamentais (privacidade, propriedade, não discriminação) a uma população. E mesmo que este entendimento não explicite a finalidade desses direitos, eles só se realizariam em ambientes já democratizados, ou seja, em ambientes que garantam o controle da população sobre as decisões políticas, permitindo que essa usufrua desses direitos e mantenha sua provisão. E independentemente da perspectiva adotada (seja a primeira, a segunda, ou ambas), nenhuma organização internacional poderá ser considerada democrática se essas forem as visões adotadas sobre o que é democracia (DAHL, 1999).

Para o autor, a primeira grande dificuldade que surge ao discutir o caráter democrático de uma instituição é definir o limite entre o que é democrático e não democrático. Não só a escala entre o ideal democrático e a forma como a democracia se realiza é contínua, como a separação é impossivel de ser delimitada. Quais direitos fundamentais devem estar presentes para tornar um sistema democrático ou qual a intensidade do controle da população sobre os decisores para garantir a democracia, são elementos muito difíceis de serem precisados. E as organizações internacionais tampouco podem ser definidas segundo esse limiar.

A delegação da autoridade e do poder se dá devido ao elevado número de cidadãos e à complexidade da administração dos problemas coletivos. Internacionalmente, o número de cidadãos envolvidos e a elevada abstração das questões (fome, pobreza, educação e meio-ambiente são temas caracterizados como universais), os colocam além da capacidade imediata de entendimento e de posicionamento da maioria. (DAHL, 1999, pág. 24). A percepção de um distanciamento das questões com relação à realidade imediata do cidadão seria um dos fatores que propiciariam a ausência de um posicionamento mais claro do grande público com relação às questões internacionais. Para Dahl, o que se observa é o conhecimento mais sistemático e envolvimento mais intenso por parte de setores específicos que, por alguma razãon', se conectariam com tais temas.

11 Experiência concreta, familiaridade pessoal, laços profissionais e sociais, dados e conhecimento de histórias relevantes seriam fracos ou mesmo ausentes para o grande público com relação às questões internacionais, sendo facilmente preenchidos por imagens e impressões trazidas pela grande mídia. Accountability seria destinado a uma específica parcela da população. (DAHL, 1999, p. 24). 
Assim, as decisões cruciais de política externa são tomadas sem se prestar contas à maioria dos cidadãos. Muitas vezes, a ausência desse accountability se dá devido à distância entre a rotina do cidadão e os problemas de ordem internacional, promovendo a ignorância ou o próprio desinteresse do cidadão sobre essas questões. Portanto, dada à ausência de posicionamentos sobre assuntos internacionais, as decisões são tomadas com base no bem comum. Contudo, a definição de bem comum e de como alcançá-lo é outro enorme problema. Sua obtenção pode partir de uma perspectiva substantiva (felicidade, bem-estar, utilidade, alocação justa etc.) ou procedimental (determinação e validação de decisões por maioria eleitoral, decisão judicial etc.), onde a solução substantiva e a procedimental dependem uma da outra. Porém, como não há acordo quanto aos termos substantivos, a maioria dos países democráticos aceita a solução procedimental como suficiente para a definição do bem comum (DAHL, 1999).

Se uma sociedade fosse homogênea, onde todos seus indivíduos compartilhassem os mesmos interesses, não haveria conflitos de posição ou, em outras palavras, de conciliação de interesses divergentes, facilitando a determinação do bem comum. Contudo, as sociedades são heterogêneas. E ao se transferir para o plano internacional, essas diferenças tendem a se tornar ainda mais fortes, o que dificulta ainda mais a determinação desse bem.

No âmbito internacional, a virtude cívica é muito fraca para se sobrepor aos interesses individuais e de grupo, pois o tecido social que vincularia indivíduos não teria o apoio institucional dado pelo Estado nem a produção de vinculações políticas via cidadania. Portanto, a fraqueza na construção de visões e de interesses de uma maioria em termos internacionais mostra que ela está inadequadamente representada nas decisões das instituições internacionais. 0 debate público, nesse caso, configura-se de forma unilateral e incompleta e, no fim, os interesses de líderes políticos e ativistas prevalecem nesses âmbitos decisórios.

Para Dahl, a única forma de uma organização internacional se tornar democrática é garantindo oportunidade de participação política, de influência sobre as decisões e de controle eficiente sobre os tomadores de decisão. Para isso, seria necessária a realização de debates públicos, com a representação e participação de diferentes posicionamentos, de modo a informar melhor os cidadãos a respeito dos temas discutidos e suas diferentes perspectivas. Adicionalmente, seria necessária a criação de partidos que abrangessem os diferentes posicionamentos internacionais, ou mesmo a incorporação, pelas agendas políticas partidárias já existentes, de uma orientação ideológica para posicionamento tanto em política externa quanto em política internacional, por parte do cidadão comum. Além disso, seria também necessário estabelecer a eleição de representantes nessas organizações internacionais, criando mecanismos diretos de delegação, representação e controle sobre o tomador de decisão.

Entretanto, como viabilizar um procedimento democrático internacional? A questão de escala torna-se um grande complicador, pois envolveria milhões de pessoas dos mais diversos grupos sociais e formas de organização política. Além disso, o processo ainda em construção de um tecido institucional internacional que possibilite o estabelecimento de procedimentos de participação nestas instâncias é também outro grande desafio para a democratização de uma organização internacional. Por mais que já existam alguns mecanismos de participação em larga escala (como a internet), seu escopo ainda é muito restrito quando comparado aos processos 
tradicionais de participação democrática em um Estado, criando, portanto, questionamentos que facilmente poderiam deslegitimar todo o processo (DAHL, 1999, p. 31).

Assim, como as organizações internacionais estendem e distanciam demasiadamente o processo de delegação, elas não podem ser consideradas democráticas. Mas o desafio de legitimá-las permanece, pois a governança global de bens públicos globais só ocorre no âmbito dessas organizações (DAHL, 1999, p. 32). E elas são válidas, porque criam normas e informações que permitem Estados e outros atores a coordenarem seu comportamento mutuamente de maneira benéfica, promovendo a cooperação internacional e ajudando a construir arranjos regulares que limitem os abusos de atores não estatais. Por isso, as instituições de governança global não devem ser apenas legítimas, mas também devem ser percebidas como legítimas (BUCHANAN \& KEOHANE, 2006, p. 408). Mas como legitimá-las se não são democráticas?

E essa mesma questão se reproduz no caso antártico: como legitimar o Sistema do Tratado Antártico se ele não é democrático? Tanto a posição de Moravcsik (que entende organizações internacionais como democráticas de forma pragmática) quanto a posição de Dahl (que rejeita a possibilidade de democracia nessas instituições) argumentam que a governança global apresenta um déficit democrático (parcial ou completo) para a sua viabilização. E ambos os autores identificam que a complexidade das questões referentes ao âmbito internacional coloca a delegação no processo decisório como a melhor (Moravcsik) ou como a única (Dahl) solução para a governabilidade nessa esfera. Mas a convergência entre os dois autores não vai além. Para Moravcsik, a delegação e o isolamento burocrático tornam as organizações internacionais mais representativas (pois evitam a influência de interesses particulares organizados). Para Dahl, a delegação do poder político nas organizações internacionais corrobora o seu caráter inevitavelmente não democrático.

Dahl afirma que é necessário pensar em outras formas de legitimação para além do formato democrático. Para ele, as organizações internacionais são denominadas "sistemas burocráticos de barganha" nos quais a hierarquia é justificada pela diferença de conhecimento e expertise daqueles que governam. E é nessa diferença que a legitimidade deve se apoiar (DAHL, 1999, p. 33). No caso antártico, a hostilidade das condições ambientais somada à intocabilidade da região demandam a necessidade de grande expertise sobre as práticas antárticas, tanto em seu processo decisório quanto em sua operação, legitimando o isolamento desse sistema burocrático de barganha. Assim, nem Estados ou organizações exteriores ao Tratado, nem mesmo cidadãos comuns teriam o conhecimento, o preparo ou mesmo a via procedimental para participar, deliberar ou mesmo serem representados nas práticas antárticas.

Para Buchanan e Keohane (2006, p. 406), a governança global de instituições ainda é nova, em evolução e caracterizada por desacordos quanto a objetivos e padrões de justiça. No caso do Tratado Antártico, não é consenso se o mais importante é a participação de todos nas atividades e nas decisões no continente, ou se a exclusividade deve prevalecer para a garantia da proteção da região. Não se definiu se o justo é a transformação da Antártica em patrimônio comum da humanidade ou se ela deve ser destinada aos Estados que reivindicam sua soberania territorial.

O caráter recente das instituições de governança global faz com que a democracia seja esperada, em seu âmbito, como mais uma etapa em seu processo de consolidação. Contudo, na ausência de mecanismos democráticos, a legitimidade dessas instituições pode ser colocada em 
xeque. Esse é o caso do Sistema do Tratado Antártico e de todas as críticas relacionadas à sua hierarquia interna e à sua exclusividade externa.

Buchanan e Keohane (2006) definem a legitimidade das instituições de governança global em dois sentidos: um sentido normativo (o direito de governar) e um sociológico (crença no direito de governar). Já o comando (ruling) baseia-se em promulgar regras e assegurar comprometimentos das partes (que aderem aos custos e benefícios de se fazer parte da instituição). Dessa forma, para ser legítima, a instituição deve não só assegurar àqueles que governam o seu direito de governar, mas também que os atores internos e externos creiam nesse direito de governar por aqueles que o fazem. É nesse primeiro ponto que o Sistema do Tratado Antártico enfrenta dificuldades.

Os doze primeiros signatários aferiram aos Estados membros consultivos o direito de tomar decisões sobre a administração da região. Eles passaram a deter o comando (ruling), definindo as regras e assegurando que todo novo membro, ao fazer parte do STA, aceitasse as determinações do tratado e de seus protocolos subsequentes. Contudo, vários atores externos não creem na exclusividade apregoada pelos membros consultivos. Eles defendem que a Antártica deveria ser tratada como patrimônio comum da humanidade, portanto governada por algum órgão representativo de toda sociedade internacional (no caso, as Nações Unidas), sem exclusões.

Para os autores, devido ao ambiente de desacordo moral e de incerteza quanto à justiça, a legitimidade torna-se relacionada ao requerimento da aceitabilidade de uma moral mínima. No caso, o Sistema do Tratado Antártico vem se consolidando ao longo do tempo. Desde 1961, novos Estados vêm aderindo ao Tratado (muitos ascendendo como membros consultivos), o que mostra que os Estados membros do STA estão conseguindo lidar com o questionamento externo da legitimidade do seu arranjo normativo, ou seja, garantindo uma mínima aceitabilidade moral de sua atuação na governança do território antártico o que leva a esse movimento contínuo de novas adesões.

Segundo Buchanan e Keohane, uma legitimidade não baseada em critérios democráticos pode ser alcançada por uma instituição por meio de aspectos epistêmicos. Esses aspectos epistêmicos - ou counting principles, segundo Rawls (1971) - são instituições definidas como legítimas por apresentarem uma aceitabilidade moral mínima, por fornecerem mais benefícios quando comparadas com outros arranjos e, por apresentarem uma integridade institucional em sua configuração. Dessa forma, quanto mais ela satisfaça esses critérios, mais legitimamente ela seria considerada (BUCHANAN \& KEOHANE, 2006). Entretanto, há limitações na conferência desses critérios substantivos de legitimidade: não só há desacordo sobre como julgar se uma instituição os apresenta satisfatoriamente ou não, como também se a configuração dessa instituição seria a mais adequada ou justa para cumprir esses critérios e se legitimar.

Dessa forma, as instituições de governança global devem apresentar três virtudes epistêmicas em sua atuação que as levaria a cumprir esses critérios substantivos de legitimidade. Primeiramente, a produção de informações confiáveis que sustentariam a função principal de coordenação de ações (principalmente nos ambientes de incerteza onde foram criadas). No caso, essa produção de informação confiável satisfaria o counting principle de produção de ambientes mais benéficos. Em segundo lugar, as virtudes epistêmicas se 
refeririam à transparência, consequência imediata do accountability prestado aos apoiadores dessas organizações. A transparência garantiria o acesso a informações que demonstrem a eficiência e efetividade dessas organizações em termos de sua própria atuação. Nesse ponto, a transparência se referiria à aceitabilidade moral mínima. E, por fim, a terceira virtude epistêmica é a capacidade dessas organizações em rever seus próprios termos de accountability (referindo-se ao counting principle da integridade institucional). A externalidade causada pela difusão da informação provida por essas organizações deve permitir o próprio questionamento de suas performances e a mudança necessária para que elas continuem a ser legitimadas no exercício de suas funções (BUCHANAN \& KEOHANE, 2006).

As virtudes epistêmicas, portanto, facilitam a revisão crítica dos objetivos e sucessos de organizações internacionais, por meio de interações com agentes e organizações externas a elas. Esses atores externos, denominados atores externos epistêmicos, reúnem as informações fornecidas, conformando o ambiente no qual a instituição existe, atua e responde. Eles coordenam seu apoio a essas instituições por meio da capacidade comum de serem movidos por razões morais compartilhadas, acompanhando e legitimando a atuação dessas instituições internacionais de governança global (BUCHANAN \& KEOHANE, 2006).

O julgamento sobre a legitimidade de uma organização possibilita um apoio coordenado entre os atores externos epistêmicos, baseado em razões morais compartilhadas que fornecem um critério, um padrão mínimo para determinar se essas instituições devem ou não continuar a serem apoiadas por eles (BUCHANAN \& KEOHANE, 2006, p. 412). Assim, a legitimidade é posta em xeque pelos atores epistêmicos se a prática dessas instituições internacionais se distancia de seus objetivos (ou das razões de sua existência), podendo o critério da integridade institucional Ihes ser conferido ou negado.

Portanto, o accountability nas organizações internacionais ocorre via atores externos epistêmicos, que compartilham um padrão moral mínimo com as instituições por meio da observação da coerência de suas ações com seus propósitos essenciais, configurando o canal de accountability entre elas e a sociedade civil transnacional. O accountability falhará somente quando o papel de uma instituição para o cumprimento de seus objetivos não estiver claro para os atores externos epistêmicos

Assim, a legitimidade institucional das organizações internacionais de governança global depende do ambiente institucional mais amplo, para além delas próprias, onde os atores externos organizados atuariam como legitimadores, pois são parte constitutiva do accountability realizado. Por consequência, as instituições internacionais de governança global não necessitariam apresentar elementos democráticos em sua própria constituição, pois como visto a partir de Dahl, elas jamais serão democráticas ou, segundo Moravcsik, pragmaticamente elas jamais apresentarão um padrão ideal de democracia. A legitimidade dessas instituições fundamenta-se na importância da qualificação de seus decisores (o que afasta a possibilidade de uma participação irrestrita), e no accountability prestado aos atores externos epistêmicos que operam junto à sociedade civil transnacional, onde estes podem manter ou não o apoio e o reconhecimento dessas instituições por meio da avaliação de sua integridade institucional, dos benefícios comparados fornecidos por sua atuação e por sua aceitabilidade moral mínima. 
No Sistema do Tratado Antártico, como já visto, o critério da qualificação técnica dos decisores é o pilar da normatização das atividades no continente. A fragilidade e o conhecimento limitado do ambiente, somados às suas condições inóspitas, fundamentaram a importância da atuação de caráter exclusivamente científico na região, onde a exigência de uma capacidade logística e técnica tornou-se o elemento garantidor da atuação permanente na Antártica, portanto balizador da aquisição do status consultivo no Tratado.

Já a atuação dos atores externos epistêmicos ficou a cargo do Comitê Científico para a Pesquisa Antártica (SCAR), que pertence ao Conselho Internacional de Uniões Científicas (ICSU). O ICSU possui status consultivo no Conselho Social e Econômico das Nações Unidas (UNESCO), no Conselho Econômico e Social (ECOSOC), na Organização para Agricultura e Alimento (FAO), além de relações de trabalho na Organização Internacional do Comércio (ITO), na Organização Mundial da Saúde (WHO) e na Organização Mundial de Meteorologia (WMO).

O SCAR é responsável pelo aconselhamento científico no sistema de áreas protegidas no continente (ASPA - Antarctic Specially Protected Area) e pelo melhoramento da disponibilidade dos dados científicos para a sociedade internacional. Portanto, o SCAR garante uma gama de interações institucionais para além do Sistema do Tratado Antártico, envolvendo diversos atores técnicos que atuam como apoiadores e controladores da orientação científica das atividades na região. O SCAR é o principal ator externo epistêmico que confere legitimidade ao STA independentemente dos questionamentos sobre seu teor democrático.

Enquanto o Sistema do Tratado Antártico for capaz de garantir a manutenção da paz, a pesquisa científica e a preservação ambiental por meio de processos decisórios informativos, transparentes e capazes de se ajustar a novas circunstâncias, os atores epistêmicos externos (no caso a comunidade científica e as organizações internacionais especializadas) continuarão a legitimar o arranjo existente. Essa legitimidade é baseada não no teor democrático do Sistema do Tratado Antártico, mas sim em sua capacidade de prover uma aceitabilidade moral mínima de suas atividades, de se apresentar como a melhor solução institucional para a governança antártica e por seguir cumprindo os propósitos pelos quais foi criado.

\section{Considerações finais}

O Sistema do Tratado Antártico é um caso exemplar do debate referente ao déficit democrático em organizações internacionais de governança global. O surgimento do Tratado veio da necessidade de se administrar uma região sensivel e estratégica de forma cooperativa, ao mesmo tempo em que o controle da participação se justificava na importância de se suspender reivindicações por soberania e de se manter atividades orientadas para fins pacíficos que resultassem em um aprofundamento do conhecimento sobre a região. Contudo, a aceitação do Tratado Antártico pela sociedade internacional não foi unânime.

Críticas latentes de que o tratado fosse antidemocrático devido à sua hierarquização interna e ao seu exclusivismo externo sempre foram levantadas. A hierarquização interna se dava pela distinção entre membros consultivos e não consultivos, onde o processo decisório 
controlado pelos primeiros e as normas elaboradas pelos mesmos interditavam ações autônomas por parte de cada Estado. Ao passo que a exclusividade externa se dava na aceitação dessa estrutura como condição de participação na Antártica e, por mais que se tenha tornado permanente o convite de membros não consultivos aos encontros, isso não se estendia a organizações internacionais, principalmente a ONU. O STA e seus membros sempre rejeitaram a ideia de transformar a Antártica em patrimônio comum da humanidade, o que acarretaria em uma universalização da participação.

Essas críticas ao caráter não democrático do arranjo colocaram em xeque a legitimidade do Sistema do Tratado Antártico. Porém, a cada ano, mais Estados aderem ao Tratado, corroborando essa estrutura. Por isso, as abordagens de Andrew Moravcsik (2004), Robert Dahl (1999) e Buchanan \& Keohane (2006) a respeito do déficit democrático em organizações internacionais de governança global auxiliam no entendimento dessa questão. Moravcsik afirma que organizações internacionais não podem ser avaliadas apenas pelo caráter normativo da democracia. A complexidade dos temas, o distanciamento da rotina dos cidadãos e o risco da influência de grupos particulares levam à delegação do poder de decisão e ao isolamento dessas burocracias especializadas. Portanto, o julgamento deve se basear na viabilidade pragmática da democracia, onde a participação direta não é a melhor opção.

Dahl já visualiza que organizações internacionais de governança global jamais serão democráticas. O parcial desconhecimento que o cidadão comum teria a respeito dos temas internacionais é somado à pluralidade dos seus interesses no âmbito doméstico, onde estes encontram canais já estabelecidos de participação e um impacto mais imediato de suas intervenções. Como consequência, esse cidadão enfrenta uma maior dificuldade na formação de sua opinião e em seu posicionamento quanto às temáticas globais, não acessando os canais pelos quais ele poderia participar mais diretamente na formulação das políticas e no processo decisório das instituições internacionais de governança global. Considerando que a democracia moderna implica mecanismos de participação social e ativismo político, de deliberação pública e de representação política do cidadão nas organizações políticas (PLOTKE, 1997), é inevitável que a transposição desses mecanismos não seja automática para o âmbito internacional.

E, por fim, considerando que a legitimidade é o direito reconhecido de se regular um conjunto de questões, tornando-as válidas e considerando-as em quaisquer processos decisórios relacionados, Buchanan e Keohane apontam que o fundamento da legitimidade das organizações internacionais de governança global estaria num ponto externo a elas. Atores externos epistêmicos promoveriam o accountability dessas organizações junto à sociedade civil transnacional, por meio do acompanhamento das informações compartilhadas de forma transparente e também por meio da observação da capacidade dessas mesmas organizações em responder e rever seus procedimentos. Assim, os atores externos epistêmicos que compartilhassem uma moral mínima com essas organizações, avaliariam os benefícios relativos de sua atuação e também sua integridade institucional, legitimando-as.

Assim, é possível entender o crescimento e a consolidação do Sistema do Tratado Antártico a despeito das críticas à sua hierarquia interna e ao seu exclusivismo externo. A complexidade que envolve seu ambiente juntamente à sua vulnerabilidade a conflitos 
corroboram o critério da expertise na tomada de decisão. Ao passo que sua orientação para atividades de fins pacíficos e científicos garante sua virtude epistêmica aos olhos dos atores externos, o que vem conferindo sua legitimidade perante a sociedade internacional.

Portanto, o estudo do surgimento e consolidação do Sistema do Tratado Antártico apresenta um caso exemplar para o entendimento de que o déficit democrático não é impeditivo para a legitimidade das organizações internacionais de governança global. O elemento crucial é entender que as idiossincrasias desse nivel de análise requerem outros elementos balizadores da legitimidade.

\section{Referências bibliográficas}

AVRITZER, Leonardo. 2007. Sociedade civil, instituições participativas e representação: da autorização à legitimidade da ação. Dados - Revista de Ciências Sociais, v. 50, n. 3.

BECK, Peter J. 1986. The International Politics of Antarctica. New York: St. Martin's Press.

BUCHANAN, Allen \& KEOHANE, Robert 0. 2006. The legitimacy of global governance institutions. Ethics \& International Affairs, v. 20, n. 4, p. 405-437.

DAHL, Robert. 1999. Can International Organizations Be Democratic? A Skeptic's View. In: Shapiro, Ian \& Hacker-Cordon, Casiano (eds.). Democracy's Edges. Cambridge: Cambridge University Press, p. 19-40.

DRYZEK, J. S. 1996. Democracy in capitalist times. Ideals, limits, and struggles. NY: Oxford University Press. FERREIRA, Felipe Rodrigues Gomes. 2009. O Sistema do Tratado da Antártica: evolução do regime e seu impacto na política externa brasileira. Brasília: Fundação Alexandre de Gusmão.

FUCHS, V. E. 1983. Antarctica its history and development. In: Antarctic resources policy. Scientific, legal and political issues. Cambridge University Press.

HOWKINS, Adrian. 2013. The significance of the frontier in Antarctic history: how the US West has shaped the geopolitics of the far south. In: The Polar Journal v. 3, n 1, p. 9-30.

LAVALLE, Adrian G. et. Al. 2006. Representação política e organizações civis. Novas Instâncias de mediação e os desafios da legitimidade. RBCS, v. 21, n. 60.

MORAVCSIK, Andrew. 2004. Is There a 'Democratic Deficit' in World Politics? A framework for Analysis. Government and Opposition Opposition - An International Journal of Comparative Politics, v. 39, n. 2, p. 336-363.

PLOTKE, David. 1997. Representation is Democracy. Constellations, v. 4, $n^{\circ} 1$.

SHADIAN, Jessica, TENNBERG, Monica. 2009. Legacies and changes in Polar Sciences. Historical, legal, and political reflections on the International Polar Year. Ashagate Publishing Limited.

TRIGGS, Gillian D. 2008. The United Nations in Antarctica? A watching brief. In: TRIGGS, Gillian D. The Antarctic Treaty Regime. Law, environmental and resources. Cambridge University Press. 
VICUÑA, Francisco. 1983. Antarctic resources policy: an introduction. In: Antarctic resources policy. Scientific, legal and political issues. Cambridge University Press.

VICUÑA, Francisco. 1988. The distribution of powers within the regime: models and alternatives for accommodation. In: Antarctic mineral exploration. The emerging legal framework. Cambridge University Press.

VICUÑA, Francisco. 1988. The evolution of the system of Antarctic cooperation and the development of resources. In: Antarctic mineral exploration. The emerging legal framework. Cambridge University Press.

ZAIN-AZRAAI. 2008. Antarctica: the claims of 'expertise' versus 'interest'. In: TRIGGS, Gillian D. The Antarctic Treaty Regime. Law, environmental and resources. Cambridge University Press.

Recebido em: 24 maio 2015

Aceito em: 22 junho 2015 